\title{
Scientists' Uncertainty and Disagreement about Global Climate Change: A Psychological Perspective
}

\author{
Thomas R. Stewart \\ University Center for Policy Research. The University at Albany, \\ State University of New York, U.S.A.
}

Since there are major gaps in scientific knowledge about the greenhouse effect, policy makers are forced to rely on scientists' judgments about the rate of climate change and its effects. It now appears that significant policy decisions will have to be made despite continuing uncertainty and disagreement among scientists. The best that policy makers can do is look for guidance in the best available expert judgment. But when the best experts express great uncertainty and disagree, as seems to be the case with the greenhouse effect, policy makers are unsure about how to proceed. Despite its importance, scientific judgment about the greenhouse effect has not been systematically studied. Psychological research on expert judgment and decision making provides theory, methods, and empirical results that can be used to study judgments based on uncertain and incomplete data and can help to explain the sources of expert uncertainty and disagreement regarding the greenhouse effect. Possible explanations are discussed.

Puisqu'il existe des lacunes importantes dans notre connaissance scientifique de l'effet de serre, les décideurs politiques sont forcés de dépendre des jugements des scientistes sur les taux de changement climatique et ses effets. Il apparaît maintenant que des décisions politiques significatives devront être prises en dépit de l'incertitude continue et des désaccords entre les scientistes. Le mieux que peuvent faire les décideurs politiques est de suivre les avis des meilleurs jugements d'expert disponibles. Mais lorsque les meilleurs experts expriment une grande incertitude et sont en désaccord, comme ce semble être le cas pour l'effet de serre, les décideurs politiques ne savent plus très bien comment procéder. En dépit de son importance, le jugement scientifique concernant

Requests for reprints and correspondence should be sent to Thomas R. Stewart, University Center for Policy Research, Milne 300, University at Albany, State University of New York, Albany, New York 12222 U.S.A. Phone: (518) 442-3850; Fax (518) 442-3398; BITNET: TS460@ALBNYVMS

Preparation of this paper was supported by the National Science Foundation (Division of Social and Economic Science) under Grant SES90-11868.

(C) 1991 International Union of Psychological Science 
l'effet de serre n'a pas été étudié systématiquement. La recherche psychologique sur le jugement expert et la prise de décision fournit une théorie, des méthodes de recherche et des données empiriques qui peuvent être utilisés pour étudier des jugements basés sur l'incertitude et des données incomplètes et qui peuvent aider à mieux comprendre les sources d'incertitude chez les experts, ainsi que leurs désaccords. Des explications possibles pour l'incertitude et le désaccord des scientistes concernant l'effet de serre sont présentées.

\section{INTRODUCTION}

Global climate change due to the "greenhouse effect" has become a central issue in global change research. In order for society to respond in an appropriate and timely fashion to future climatic change which may occur more rapidly than ever before, it must be able to understand and predict the causes and consequences of such change. As Professor Pawlik argues in this volume, global change has several characteristics that prevent direct perception of its progress and may lead to inappropriate responses. Society must therefore depend on experts for the understanding of global change that is necessary for appropriate response. With regard to global climate change, however, there is apparent uncertainty and disagreement among experts.

Uncertainty and debate among scientists about the greenhouse effect is not new, but its public exposure has increased dramatically in recent years. Examples of disagreement among scientists regarding the greenhouse effect are readily available in the pages of Science and the New York Times. For example, sceptics such as Richard Lindzen and Jerome Namias, both highly respected atmospheric scientists, state in a letter to President Bush written in late September, 1989, that: "Current forecasts of global warming are so inaccurate and fraught with uncertainty as to be useless to policy makers." (Stevens, 1989). On the other hand, James Hansen, also highly respected, has been quoted (Kerr, 1989a) as saying: "It's just a logical conclusion that the greenhouse is here."

Although scientists generally agree that greenhouse predictions are uncertain, they differ sharply on how much uncertainty should be associated with the predictions. The following quotes from Kerr (1989a) illustrate disagreement among scientists with regard to one area of uncertainty - the likelihood that recent unusually warm years and the observed increase in global mean temperature observed over the last 100 years are associated with the greenhouse effect (emphasis on expressions of uncertainty added):

"... the earth was getting warmer ... with $99 \%$ confidence." (Hansen, direct
quote)

"Confidence in detection [of the greenhouse effect] is now down near zero." (Schlesinger, direct quote) 
"By my intuitive reasoning, the greenhouse signal has been detected at an $80 \%$ probability." (Schneider, direct quote)

"... with a high degree of confidence we could associate the warming and the greenhouse effect." (Hansen, direct quote)

" 1987 was so hot, so much warmer than the average of the previous 30 years, that its warmth had only a $1 \%$ chance of being a random quirk of the climate system." (Conclusion attributed to Hansen)

"... confidence of just $70 \%$ that it was an exceptional year." (conclusion attributed to Solow)

"It is tempting to attribute [the 0.5 degree $\mathrm{C}$ warming of the past 100 years] to the increase in greenhouse gases. Because of the natural variation of temperature, however, such an attribution cannot now be made with any degree of confidence." (According to Kerr, the only passage agreed upon by the participants in the Workshop on Greenhouse-Gas-Induced Climatic Change held in Amherst, Massachusetts, May, 1989)

Scientists also disagree about how long it will take to reduce uncertainty about greenhouse predictions by scientific study. For example, several scientists have argued that uncertainty about greenhouse predictions will be substantially reduced within five years (Jastrow, 1990; Lindzen, 1990; Nierenberg et al., 1989), while others argue that a much longer period will be required (Roberts, 1989).

In general, four types of uncertainty and disagreement among scientists about the greenhouse effect can be identified:

1. Uncertainty and disagreement about predictions of the magnitude and rate of global warming and its effects.

2. Disagreement about the level of uncertainty that should be attached to predictions.

3. Disagreement about how long it will take to substantially reduce uncertainty through scientific study.

4. Disagreement about what policy actions are justified, given the current uncertainty about the greenhouse effect.

As a result of these uncertainties, policy makers are not receiving a clear signal from scientists about the seriousness of the greenhouse effect and its consequences. When scientists disagree, decision makers are left in a quandary. Policy decisions cannot wait for scientific study to resolve the uncertainty; even doing nothing is a policy decision. The best that policy makers can do is to look for guidance in the best available expert judgment. But when the experts are uncertain and disagree, as seems to be the case for the greenhouse effect, policy makers are unsure about how to proceed. In the absence of consensus, which experts should they believe? 
In the case of the greenhouse effect, both the extent of disagreement among scientists and the reasons for disagreement are poorly understood. While the reports of scientific panels, congressional testimony, statements by the more vocal scientists, and press reports suggest significant disagreement, the views of the majority of scientists who prefer not to take a public stand, are unknown. Despite scientists' abhorrence of "science by consensus", beliefs about the prevailing point of view among scientists are often cited to support scientific conclusions. For example, in recent letters to Science two scientists supported their views by referring to prevailing beliefs in the scientific community. Nierenberg (1990) stated that: "I am certain that most working climatologists believe that there has been no significant increase in temperature in the last 100 years", and Jastrow (1990) supports his comment that clouds and oceans introduce "enormous uncertainties" into greenhouse predictions by stating that: "This view is widely held in the climatology community."

When applied to an area as controversial as greenhouse research, such statements about prevailing beliefs can be seriously misleading. Since the climatological community has not been systematically surveyed, the prevailing belief is unknown. Even if it were known, no scientist would seriously argue that consensus alone is sufficient to establish truth. It would be necessary to establish the reasons for those disagreements and, if possible, to resolve them through scientific reasoning. If such resolution is not possible, then an appropriate level of uncertainty must be maintained.

The reasons for scientists' differing judgments about the greenhouse effect have not yet been explored in any detail. In the absence of systematic study, a variety of explanations may be suggested. One that naturally arises is that scientists' views are influenced by their political values. This, and two alternative explanations, based on psychological research are described in the following.

\section{THE POLITICAL EXPLANATION FOR SCIENTISTS' DISAGREEMENT}

The political stakes in the greenhouse debate are obvious. Strong policies designed to reduce $\mathrm{CO}_{2}$ emissions would also result in energy conservation and reduced emissions of other pollutants, thus contributing to goals long sought by environmentalists. Those same policies would also impose an economic burden on industry and individuals. This somewhat oversimplified view is compelling to the layperson, and it leads to a simple explanation for disagreement among scientists: That scientists form opinions based on their political views and their perceived self-interest and then merely select evidence that supports their opinions. 
The political explanation for scientific disagreement is used by scientists as well as lay people. According to Roberts (1989), Stephen Schneider, a wellknown scientist from the National Center for Atmospheric Research, denounced a report recently prepared by three prominent scientists as a "political document". In a letter to Science, one of the authors of that report (Jastrow, 1990), suggested that it was the report's critics who were politically motivated:

The vituperative nature of some of the criticisms [of the report by Nierenberg, Jastrow, and Seitz (1989)] suggests that more than technical issues are involved.... Critics ... would like to see the government move now towards limits on $\mathrm{CO}_{2}$ emissions. That appears to be the policy issue underlying the technical argument. (Emphasis added.)

In the absence of systematic study of reasons for disagreements among scientists, the political explanation may achieve wide acceptance. Excessive reliance on political explanations for scientific controversy is damaging, however, both to scientists and to the effective use of science in public policy formation. Although scientists' judgments may be influenced to some extent by their values, it is important to explore other explanations as well.

\section{AN ALTERNATIVE EXPLANATION: THE NATURE OF THE JUDGMENT PROCESS}

Scientists simply don't know as much as they would wish about the greenhouse effect, but public policy decisions cannot be deferred until they have complete information. Scientists are asked, therefore, to bridge the gap between available data and the judgments that are required by decision makers. As Hammond et al. (1984) have pointed out, when scientists go beyond the available data to make inferences and predictions, they are using the same judgment processes that lay people use, and they are subject to the same problems. Both scientists and lay people are subject to a variety of "cognitive limitations" that affect their judgment and contribute to disagreements that are difficult to resolve (see, for example, Arkes \& Hammond, 1986; Brehmer \& Joyce, 1988; Hammond et al., 1975; Hogarth, 1987; Kahneman et al., 1982; Mumpower et al., 1987; Slovic et al., 1977). These cognitive limitations are of three kinds:

1. Irrelevant factors influence judgment (Gaeth \& Shanteau, 1984) while more relevant factors are ignored.

2. The capacity to process information is limited. As a result, only selected information is attended to, and the selection process can be biased.

3. The judgment process is inconsistent and not fully controlled.

The necessity for judgment leads to disagreements that can be traced, in part, to the fallibility of human judgment rather than to the substantive issues under consideration. This is an explanation for disagreement that is 
almost never considered by lay people outside the field of judgment and decision research.

Although Fischhoff and Furby (1983) proposed a study of the subjective aspects of judgments about climatic change, no systematic study has been done and the role of cognitive factors in the greenhouse debate is currently unknown. However, a recent article in Science (Kerr, 1989b, p.1118) describing the views of Richard Lindzen, a "greenhouse skeptic", illustrates their potential role. The author of the article states that climatic modellers criticize Lindzen because he "seems to claim he has a better climate model in his head than they have in their supercomputers". Stephen Schneider is quoted as saying: "Does he have a calculation, or is his brain better than our models?" The article includes a number of quotes from atmospheric scientists suggesting that Lindzen relies on intuition, or "philosophical" ideas rather than science, and that such assumptions lead to fundamental errors. Schneider is also quoted as saying that sceptics "count all the negative feedbacks we don't know about, and forget about the positive ones we don't know about." Several other scientists in the article are described as offering what are essentially lay persons' cognitive theories for Lindzen's disagreement with "mainstream greenhouse researchers". Jerry Mahlman characterized Lindzen's manuscript as "a whiny complaint without scientific justification". He is also quoted as saying that "Lindzen is a smart person, but I'm afraid he's confused." Kerr states that Lindzen himself describes his view of how control of atmospheric temperature works as "an idea of theological or philosophical nature".

While criticizing Lindzen's judgment, some scientists do not hesitate to offer their own. For example, Peter Stone is quoted as saying: "He's focused on one aspect, but if you look at the whole of it, I don't think you'd have a negative feedback." In addition, Alan Betts stated: "We don't fully understand moisture transport, but the model studies I have done would not support his arguments. I personally doubt they would hold."

\section{ANOTHER ALTERNATIVE EXPLANATION: THE JUDGMENT HIERARCHY}

In order to form an opinion about something as complex as the greenhouse effect, scientists must select the most important and relevant theory and results from the climatological record, empirical research, and atmospheric modelling, and then they must weigh that information and aggregate it into judgments that are the basis for their conclusions. The process of selecting, weighing and aggregating varies from one scientist to the next, and depends, among other things, on training, background, and experience.

It has been repeatedly demonstrated in research on judgment and decision making that judgments can be understood by decomposing them according 
to the relevant information available and how that information is selected and aggregated. The information on which a scientific judgment is based can be organized into a multi-level hierarchy. The judgment that is being analysed is at the top level. The lowest level of the hierarchy includes the most "objective" information available. Intermediate levels consist of judgments based on information at lower levels of the hierarchy. Those judgments, in turn, are the basis for judgments at the higher levels.

In the case of scientific judgment regarding the greenhouse effect, information and intermediate judgments could be organized into a judgment hierarchy with at least five levels:

Level 1: Includes specific studies and results as well as well-established theory. This level consists of raw data or "facts" on which judgments are based. The elements of level 1 are "objective" in the sense that they are not controversial. In other words, level 1 includes the data about which scientists agree; it is the level of consensus.

Level 2: Consists of a grouping of studies and results. Since the studies at level 1 may number in the thousands, it is necessary to reduce and simplify them by grouping related studies in some way. This may be done through influential review papers or books or by combining the work of a particular investigator or laboratory (e.g. "Smith's work shows that. ..."). There may be some disagreement among scientists regarding the most useful method for grouping level 1 data into level 2 , and about where the weight of evidence within a particular grouping falls.

Level 3: Includes the interpretation and aggregation of particular lines of research, e.g. detection of global warming in the climate record, measurement and prediction of trends in emissions of greenhouse gases, or results of global climate models. Significant disagreement is expected at this level.

Level 4: Is for broad conclusions based on the evidence included in the lower levels. This level might include conclusions about the rate of global warming, the distribution of climatic changes, and the social and economic impacts of those changes.

Level 5: Consists of policy recommendations based on the broad conclusions at level 4. Disagreements at this level are expected and they are not resolvable by scientific study alone because they involve questions of "what should be". These questions require value-based judgments about trade-offs between the costs and benefits of various actions and possible outcomes.

It seems that most scientists would prefer not to deal with the higher levels of this hierarchy, at least in public. Because of training and experience, they are more comfortable at the lower levels. Some might argue that no scientist should venture a judgment at level 4 or 5 , while others seem to be comfortable doing so. Policy makers must operate at the higher levels of the hierarchy. If scientists refuse to venture there, then policy makers will be forced to draw their own conclusions. 
Based on the hierarchy postulated earlier, several general hypotheses can be proposed:

Hypothesis 1: Scientific disagreement and uncertainty are greater at higher levels of the hierarchy than at lower levels.

Hypothesis 2: There are individual differences among scientists' with regard to expressed uncertainty and confidence in their judgments both within and across levels.

Hypothesis 3: There are individual differences among scientists regarding how to select and aggregate information at level $n$ to form a judgment at level $n+1$.

Hypothesis 4: Those individual differences can explain important disagreements at higher levels of the hierarchy.

\section{SUMMARY}

In his paper, Professor Pawlik lists five characteristics of global environmental change that are psychologically important in determining human perception and response to that change:

1. Low signal-to-noise ratio.

2. Extreme masking and delay of cause-effect gradients.

3. Psychophysics of low-probability events.

4. Social distance between actors and victims of global change.

5. Low subjective cost-effectiveness of environment conserving behaviour.

These characteristics can affect not only lay people but scientists and policy experts as well. They may affect scientists' judgment about the distribution, timing, magnitude, and effects of global climate change. They also may affect the judgments of policy experts about the appropriate responses to climate change. Research on the psychological dimensions of global change must therefore include studies of experts as well as lay people.

The results of psychological research on judgment and decision making suggest constructive alternatives to the "political explanation" for disagreement among experts about the greenhouse effect. When scientists make judgments about complex, uncertain phenomena, they are subject to the same biases and limitations that seem pervasive in human judgment. Scientists' judgments can be organized into a hierarchical structure that makes explicit the relation between information and judgment. Development of such a structure for the analysis of judgments about the greenhouse effect could lead to identification of: a) Significant causes of uncertainty and disagreement; b) issues that might be resolved through focused discussion; and c) areas where additional research might be most effective in reducing uncertainty and disagreement. 


\section{REFERENCES}

Arkes, H.R. \& Hammond, K.R. (1986). Judgment and decision making: An interdisciplinary reader. Cambridge: Cambridge University Press.

Brehmer, B. \& Joyce, C.R.B. (Eds.). (1988). Human judgment: The social judgment theory view, Amsterdam: North-Holland.

Fischhoff, B. \& Furby, L. (1983). Psychological dimensions of climate change. In R.S. Chen, E. Boulding, \& S.H. Schneider (Eds.), Social Science research and climate change: An interdisciplinary appraisal. Dordrecht, Holland: D. Reidel.

Gaeth, G.J. \& Shanteau, J. (1984). Reducing the influence of irrelevant information on experienced decision makers. Organizational Behavior and Human Performance, 33, 263-282.

Hammond, K.R., Stewart, T.R., Brehmer, B., \& Steinman, D.O. (1975). Social judgment theory. In M.F. Kaplan \& S. Schwartz (Eds.), Human judgment and decision processes (pp. 271-312). New York: Academic Press.

Hammond, K.R., Anderson, B.F., Sutherland, J., \& Marvin, B. (1984). Improving scientists' judgments of risk. Risk Analysis, 4, 69-78.

Hogarth, R.M. (1987). Judgement and choice: The psychology of decision (2nd ed.). Chichester: Wiley.

Kahneman, D.P., Slovic, P., \& Tversky, A. (Eds.). (1982). Judgment under uncertainty. Heuristics and biases. Cambridge: Cambridge University Press.

Mumpower, J.L., Renn, O., Phillips, L.D., \& Uppuluri, V.R.R. (Eds.). (1987). Expert judgment and expert systems. New York: Springer-Verlag.

Jastrow, R. (1990). [Letter to the editor]. Science, 247, 14-15.

Kerr, R.A. (1989a). Hansen ws. the world on the greenhouse threat. Science, 244, 1041-1043.

Kerr, R.A. (1989b). Greenhouse skeptic out in the cold. Science, 246, 1118-1119.

Lindzen, R.S. (1990). [Letter to the editor]. Science, 247, 14.

Nierenberg, W.A. (1990). [Letter to the editor]. Science, 247, 14.

Nierenberg, W.A., Jastrow, R., \& Seitz, F. (1989). Scientific perspectives on the greenhouse problem. Washington, DC: Marshall Institute.

Roberts, L. (1989). Global warming: Blaming the sun. Science, 246, 992-993.

Slovic, P., Fischhoff B., \& Lichtenstein, S. (1977). Behavioral decision theory. Annual Review of Psychology, 28, 1-39.

Stevens, W.K. (1989, December 13). Skeptics are challenging dire 'greenhouse' views. The New York Times, Vol. CXXXIX. 